\title{
PENGARUH KOMPETENSI KEWIRAUSAHAAN TERHADAP KINERJA USAHA KEDAI KOPI SKALA MIKRO DAN KECIL DI KOTA MEDAN
}

\author{
Muhammad Reza Aulia *) \\ *) Program Studi Agribisnis, F. Pertanian, Unika St. Thomas \\ m.reza19.mr@gmail.com
}

\begin{abstract}
This research aims to analyze the influence of entrepreneurial competency towards the business performance of micro and small scale coffee shop in Medan City. Entrepreneurial competency reflected by managerial skill, conceptual skill, social skill, decision making skill and time managerial skill. Business performance reflected by income, profit and sales volume. This research used 60 data samples of coffee shop consist of 30 unit micro scale and 30 unit small scale that were collected through snowball sampling in Medan City from February 2020 until March 2020. The data were analyzed by SEM-PLS analysis with SMART PLS 3 software. The result showed that the business performance was influenced by entrepreneurial competency both in micro and small scale model.
\end{abstract}

Keywords: Entrepreneurial competency and business performance

\section{PENDAHULUAN}

Peran UMKM dalam menggerakkan roda perekonomian nasional bukan hanya sebagai benih dari tumbuhnya bisnis besar, tapi juga sebagai penyedia produk maupun jasa yang tidak mampu diproduksi usaha besar karena kurang efisien dalam hal biaya. UMKM yang saat ini sedang berkembang salah satunya adalah bisnis kedai kopi. Kedai kopi tumbuh dengan berbagai konsep. Kedai kopi dewasa ini tidak hanya kita jumpai dipinggir jalan saja, tapi juga ada di mall dan gedung perkantoran. Tidak hanya menjual kopi dan makanan ringan, kini kedai kopi juga menjual suasana nyaman dan sentuhan emosi yang dihadirkan seperti gengsi, kebanggaan maupun kehangatan. Hal ini mendapat animo yang baik dari pecinta kopi serta menjadi gaya hidup masyarakat perkotaan.

Kedai kopi skala mikro yang biasanya terletak di pinggir jalan bermodalkan tenda dan bangku biasanya dinikmati oleh masyarakat menengah ke bawah, kopi dijual dengan harga Rp.4000 per cangkir. Namun kini hadirnya kedai kopi dengan konsep-konsep yang menarik memikat kalangan menengah atas meski dijual lima kali lipat lebih mahal. Tidak hanya menarik, kedai kopi tumbuh dengan aset yang lebih besar, mereka menggunakan mesin kopi dan berbagai furniture yang tidak murah, masyarakat Indonesia pun sudah familiar dengan model kedai kopi seperti ini.

Gambar 1 menunjukkan konsumsi kopi di Indonesia dari tahun 1990 sampai 2017 yang mengalami trend meningkat secara signifikan. Berdasarkan Gambar 1 dapat dikatakan bahwa masyarakat Indonesia senang mengkonsumsi kopi dan merupakan potensi bagi usaha yang menjadikan kopi komoditas utama dalam bisnisnya. Hal ini diperkuat hasil riset ICO 2017 yang menyatakan bahwa pertumbuhan konsumsi kopi Indonesia lebih besar dua persen dibandingkan dengan pertumbuhan dunia. 


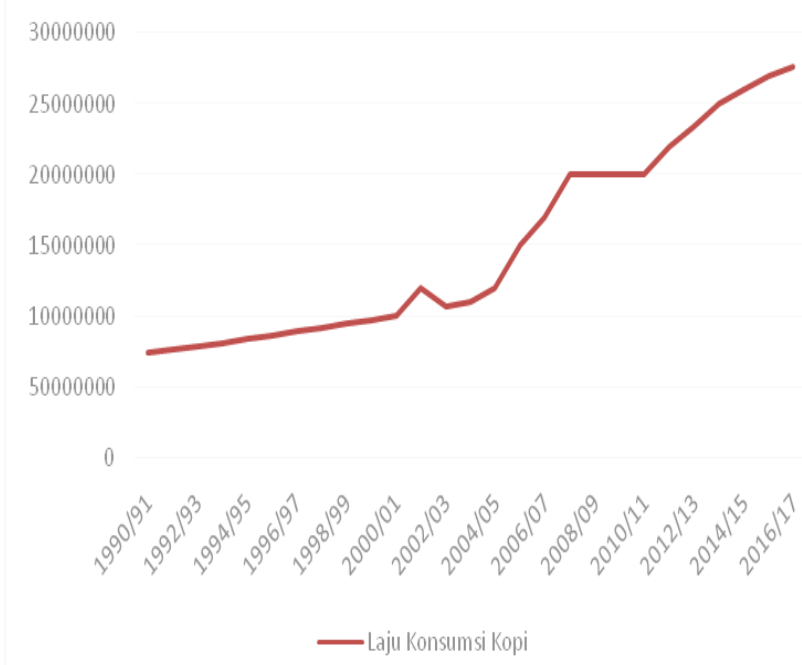

Gambar 1 Konsumsi Kopi Indonesia 1990-2017 dalam Kg Sumber: International Coffee Oraganization (ICO) 2017

Pada tahun 2015 muncul film berjudul filosofi kopi yang menceritakan tentang kecintaan terhadap kopi dan betapa berharganya kopi Indonesia. Hal ini memotivasi anak-anak muda untuk terjun kedalam dunia wirausaha untuk meningkatkan perkopian Indonesia. Hal inilah yang menyebabkan kedai kopi modern muncul dengan menawarkan halhal menarik, didominasi oleh kaula muda baik pemilik maupun pelanggannya. Tidak hanya sukses di kota besar, kedai kopi dengan aset yang besar sudah sampai ke daerah-daerah. Kedai kopi yang selama ini kita kenal hanya menawarkan fasilitas sederhana kini sudah mampu menawarkan hal-hal mewah dan menarik. Ekspansi kedai kopi modern sungguh cepat dan luas dikarenakan adanya sistem franchise (waralaba). Tidak perlu repot memikirkan bagaimana menjalankan usaha karena semua bahan input bahkan sistem sudah disediakan oleh pemilik perusahaan sehingga mitra hanya perlu menyediakan modal saja.

Euromonitor melaporkan bahwa pertumbuhan kedai kopi Indonesia mencapai angka 16 persen per tahun. Kedai kopi yang menyumbang pertumbuhan tersebut tentu kedai kopi modern dengan aset yang jauh lebih besar dari pada kedai kopi tradisional. Menjamur nya kedai kopi modern yang minimal memerlukan aset 50 juta rupiah (skala kecil) tentu berdampak pada kedai kopi tradisional yang biasanya hanya mempunyai asset dibawah 50 juta (skala mikro). Kedai kopi skala mikro tentunya memenuhi kebutuhan masyarakat menengah kebawah. Tingginya tingkat kompetisi dalam memancing konsumenkonsumen baru untuk datang tentu akan berdampak pada berkurangnya konsumen kedai kopi skala mikro.

Pesatnya pertumbuhan kedai kopi dan efek film filosofi kopi memunculkan paradigma baru, dimana tempat yang nyaman untuk berkumpul, gengsi, status sosial menjadi sebuah kebutuhan bahkan sudah merembes pada masyarakat menengah ke bawah. Hal ini menunjukkan bahwa pengunjung kedai kopi sudah mengalami disorientasi, dimana pada tahun 1990-an kedai kopi memiliki dimensi sosial tempat untuk diskusi, membicarakan masalah negeri maupun lingkungan sekitar dan sebagai gudang informasi. Dewasa ini banyak mahasiswa, anak sekolah, karyawan dengan pendapatan rendah datang ke kedai kopi modern bukan untuk berdiskusi dan membincangkan permasalahan negeri, tapi hanya untuk berkumpul dan bersenang-senang. Pelanggan kopi terpaksa harus memesan secangkir kopi dengan harga yang jauh lebih mahal dari pada kedai kopi tradisional demi untuk mencoba hal-hal baru dan 
dianggap menarik. Berbeda pada kedai kopi skala mikro, dimana masih banyak ditemukan orang-orang berdiskusi baik dengan pemilik maupun ke sesama pelanggan, walaupun sudah mulai berkurang. Pada gambar-2, tumbuhnya kedai kopi ternyata tidak sebanding dengan konsumsi perkapita masyarakat Indonesia.

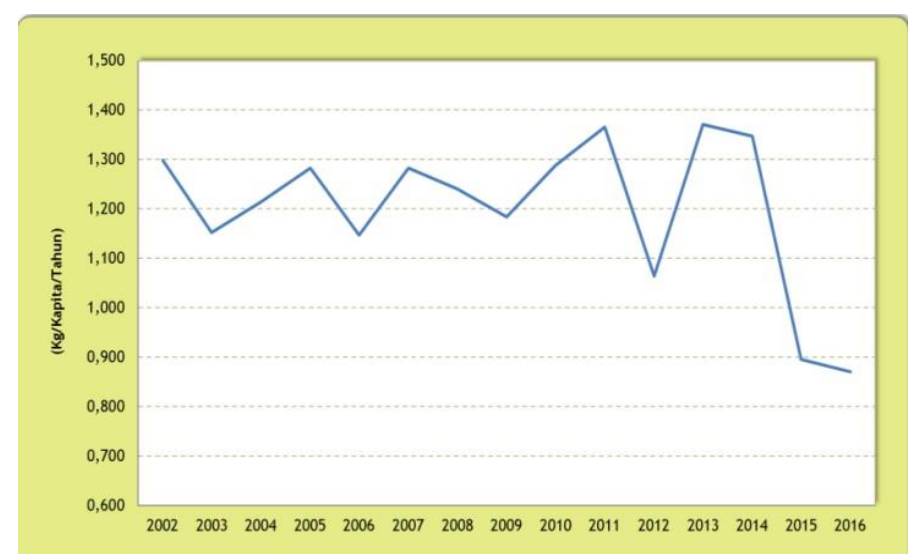

Gambar-2: Konsumsi Kopi Per Kapita 2002-2016

Sumber : International Coffee Organization (ICO), 2017

Kedai kopi skala kecil di kota Medan mengalami kenaikan, sementara kedai kopi skala mikro relatif stagnan. Kedai kopi skala kecil banyak dimanfaatkan oleh masyarakat kota untuk keperluan menikmati kopi sekaligus hiburan dimana pelanggan dapat menikmati suasana nyaman sambil bercengkrama dan istirahat melepas penat. Jumlah kedai kopi skala kecil setiap tahunnya semakin bertambah, tapi di sisi lain kedai kopi skala mikro tidak banyak bertambah karena beberapa faktor. Beberapa faktor tersebut diantaranya kedai kopi skala mikro sudah mulai sepi dan banyak ditinggalkan karena pelanggan telah mengalami disorientasi terhadap kedai kopi, sebelumnya kedai kopi memiliki tempat sebagai tempat diskusi dan gudang informasi, tapi kini orientasi pelanggan lebih ke gengsi dan prestisi. Selain itu para pelaku usaha kedai kopi diduga memiliki masalah-masalah kompetensi kewirausahaan seperti rendahnya kemampuan pelaku usaha dalam mengelola sistem informasi bisnis, manejemen keuangan dan manajemen pemasaran. Maka dari itu perlu dilakukan penelitian terkait pengaruh kompetensi kewirausahaan terhadap kinerja usaha kedai kopi skala mikro dan kecil di Kota Medan.

Pada tahun 1990-an orang-orang datang ke kedai kopi bertujuan untuk bersilaturahmi, berdiskusi dan mencari informasi. Namun dewasa ini orientasi pelanggan kedai kopi sudah berbeda, kebanyakan datang ke kedai kopi lebih untuk mencari kenyamanan, gengsi dan prestisi. Kedai kopi skala mikro dan kecil tentu memiliki perbedaan diantaranya adalah perbedaan kompetensi kewirausahaan dan hal-hal yang memengaruhinya. Semakin besar skala usaha, semakin tinggi pula kompetensi kewirausahaannya (Bergevoet, et al. 2004). Mengidentifikasi kompetensi wirausaha merupakan isu penting untuk mempercepat pengembangan kewirausahaan (Rahman et al. 2016). Kompetensi kewirausahaan berhubungan dengan kinerja, daya saing, pertumbuhan dan kesuksesan perusahaan (Tehsen dan Ramayah, 2015). Karakter seorang wirausaha, kompetensi umum dan kompetensi khusus serta motivasi yang dimiliki berpengaruh secara positif terhadap pertumbuhan usaha (Baum et al. 
2001). Hal ini menunjukkan bahwa sangat diperlukan kompetensi kewirausahaan untuk meningkatkan kinerja usaha. Kajian dan penelitian tentang kompetensi kewirausahaan kedai kopi menjadi hal yang penting. Perlu diteliti bagaimana pengaruh kompetensi kewirausahaan terhadap kinerja usaha kedai kopi skala mikro dan kecil. Oleh karena itu perlu untuk melakukan penelitian ini.

\section{LANDASAN TEORI}

\section{Kompetensi Kewirausahaan}

Kompetensi kewirausahaan adalah pengetahuan, kemampuan, sikap, keterampilan yang memengaruhi kinerja usaha. Indikator kompetensi usaha dalam penelitian ini adalah kemampuan manajerial, kemampuan konseptual, kemampuan sosial, kemampuan membuat keputusan, dan kemampuan mengatur waktu.

\section{Kinerja Usaha}

Kinerja usaha adalah gambaran mengenai hasil yang sudah dicapai dalam menjalankan usaha. Indikator kinerja usaha adalah pendapatan, keuntungan, dan volume penjualan.

\section{METODE PENELITIAN}

Penelitian ini dilakukan di kota Medan dalam jangka waktu selama 2 bulan dari bulan Februari 2020 hingga Maret 2020. Populasi sasaran yang dituju dalam penelitian ini adalah seluruh wirausaha kedai kopi Kota Medan, baik skala mikro maupun skala kecil. Belum diketahui jumlah pasti berapa kedai kopi skala mikro dan berapa skala kecil.

Kondisi di lapangan mengharuskan untuk menggunakan teknik snowball sampling, karena kesulitan mendapatakan data, sehingga sulit menentukan siapa yang harus diteliti. Melalui teknik snowball sampling, responden dalam penelitian ini berjumlah 60 orang yang terdiri dari 30 orang pelaku usaha skala mikro dan 30 orang pelaku usaha skala kecil. Hal ini sesuai dengan ukuran sampel yang direkomendasikan Ghozali dan Latan, 2015) bahwa dalam penggunaan metode PLS (partial least square) sampel sebaiknya minimal 30-100 sampel.

Variabel penelitian merupakan konsep yang dapat diukur. Variabelvariabel yang akan digunakan dalam penelitian ini terdiri dari variabel laten dan variabel manifest sebagai indikator dari variabel laten. Untuk dapat mengukur variabel laten dibutuhkan variabel indikator. Variabel indikator atau variabel manifest merupakan variabel yang menjelaskan atau mengukur variabel laten. Contohnya yaitu variabel kompetensi kewirausahaan tidak dapat diukur secara langsung, dibutuhkan variabel lainnya yang dikenal dengan sebutan variabel indikator yang dapat menjelaskan kondisi kompetensi kewirausahaan. Pada penelitian ini, kompetensi kewirausahaan dijelaskan oleh variabel kemampuan manajerial, kemampuan konseptual, kemampuan sosial, kemampuan membuat keputusan dan kemampuan mengatur waktu. Variabel manisfest atau indikator dari kompetensi kewirausahaan dapat dilihat pada tabel-1. variabel manifest atau indikator kinerja usaha dapat dilihat pada tabel -2 .

Tabel-1: Variabel Indikator Kompetensi Kewirausahaan

\begin{tabular}{ll}
\hline \multicolumn{1}{c}{ Variabel } & \multicolumn{1}{c}{ Keterangan } \\
\hline Kemampuan Manajerial & $\begin{array}{l}\text { Kemampuan mengatur atau mengelola } \\
\text { dalam menjalankan usaha untuk mencapai } \\
\text { tujuan. }\end{array}$
\end{tabular}




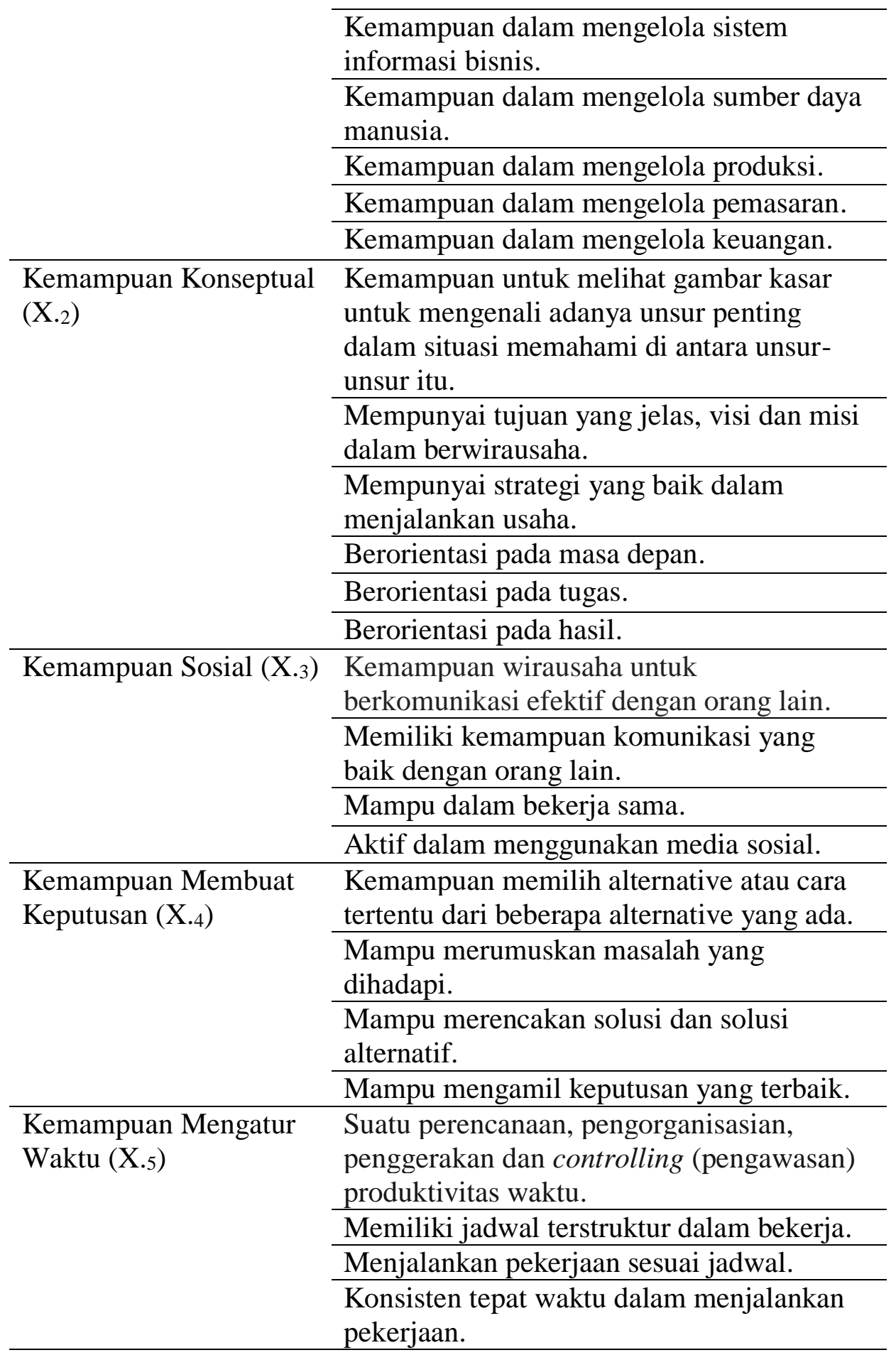

Sumber: Moeheriono 2009; Nurhayati, et al 2011; dan Isa, 2013

Tabel-2: Variabel Indikator Kinerja Usaha

\begin{tabular}{ll}
\hline \multicolumn{1}{c}{ Variabel } & \multicolumn{1}{c}{ Keterangan } \\
\hline Penerimaan (Y.1) & Total omset yang diterima \\
\hline Keuntungan (Y.2) & Total penerimaan dikurangi total pengeluaran \\
\hline Volume penjualan (Y.3) & Total produk yang terjual \\
\hline Sulal
\end{tabular}

Sumber : Kuratko dan Hodgerss 2007, Muharastri 2013 
Data yang yang telah dikumpulkan, dianalisis secara kualitatif dan kuantitatif. Analisis kualitatif menggunakan analisis deskriptif, sedangkan analisis kuantitatif menggunakan analisis PLS (Partial Least Square). Data berupa kuesioner yang telah diisi oleh responden. Partial Least Square merupakan metode analisis yang digunakan untuk menganalisis hal yang cukup kompleks yang menggabungkan regresi dengan path analysis untuk menguji hipotesis mengenai hubungan langsung maupun tidak langsung antara variabel yang diamati dan variable laten.

Kompetensi kewirausahaan dan kinerja usaha tidak dapat diukur langsung, maka diperlukan varibael manifest. Variabel manisfest dari kompetensi kewirausahaan adalah $\mathrm{X}_{1}, \mathrm{X}_{2}, \mathrm{X}_{3}$. $\mathrm{X}_{4}$, dan $\mathrm{X}_{5}$. Variabel manisfest dari kinerja usaha adalah $\mathrm{Y}_{1}, \mathrm{Y}_{2}$ dan $\mathrm{Y}_{3}$. Persamaan pemodelan PLS menggambarkan semua hubungan variabel dependen dan variabel independen didalam suatu analisis. Analisis PLS dilakukan dengan bantuan program SMART PLS 3. Program ini mampu menggambarkan hubungan-hubungan yang dibangun dalam model berdasarkan teori, sehingga mampu menganalisis faktorfaktor yang memengaruhi karakteristik kewirausahaan, kompetensi kewirausahaan dan kinerja usaha, serta hubungan dan pengaruhnya. Metode PLS dipilih berdasarkan pertimbangan bahwa seluruh variabel laten tidak dapat diukur secara langsung. Perlu dikaji factor-faktor yang memengaruhi variabel laten tersebut diantaranya karakteristik individual, karakteristik psikologis, kompetensi kewirausahaan, kinerja usaha. PLS merupakan metode dengan pendekatan varian yang bersifat predictive model, sedangkan SEM yang berbasis kovarian umumnya menguji teori (Ghozali dan Latan 2015).

Dalam PLS terdapat model pengukuran dan model struktural. Model pengukuran merupakan hubungan antara butir yang diobservasi dengan variabel laten, sedangkan model struktural penjelasan hubungna antar variabel laten. Model pengukuran harus valid dan reliabel, sedangkan model struktural dinilai dengan mengevaluasi daya penjelas (explanatory power) dan tingkat signifikansi koefisien jalur. Pengujian ini dilakukan dengan melihat $R$-square, $Q$-square, Goodnes of fit (GoF) dan F-square. R-square digunakan untuk menilai pengaruh variabel laten dependen apakah mempunyai pengaruh substantif (Latan dan Ghozali 2015). $Q$ square digunakan untuk mengukur seberapa baik nilai observasi yang dihasilkan oleh model. Nilai yang harus dicapai dapat dilihat pada tabel-6. Rule of thumb adalah sebuah standar untuk menghasilkan model yang baik. Semua syarat harus mampu dipenuhi untuk mencapai hasil yang baik.

Tabel-3: Rule of Thumb

\begin{tabular}{cc}
\hline Kriteria & Rule of Thumb \\
\hline R-square & $0.75:$ kuat $; 0.5:$ moderat; $0.35:$ kecil \\
\hline Q-square & $>0$ berarti baik, < 0 berarti tidak baik \\
\hline GoF & $0.26:$ besar, $0.13:$ medium, $0.02:$ kecil \\
\hline F-square & $0.35:$ besar, $0.15:$ medium, $0.02:$ kecil \\
\hline
\end{tabular}

Sumber : Latan dan Ghozali 2015

Dalam model PLS, model yang diuji dapat menggunakan asumsi; data tidak harus berdistribusi normal; Skala pengukuran boleh berupa nominal, ordindal, interval dan rasio; indikator boleh relfektif maupun formatif; dan tidak 
harus berdasarkan teori (Latan dan Ghozali 2015). Pengujian hipotesis dinilai berdasarkan nilai t-statistik. Kriteria untuk menolak dan menerima hipotesis yang diajukan dinilai berdasarkan perbandingan nilai t-hitung dan t-tabel. Apabila nilai thitung lebih besar dari pada t-tabel, maka hipotesis diterima. Namun apabila t-hitung lebih kecil dari pada t-tabel, maka hipotesis ditolak. Untuk mengetahui persentasi pengaruh variabel independen terhadap variabel dependen dapat dengan melihat nilai $R$-square. Nilai $R$-square yang mendekati 1 memiliki pengaruh yang sangat besar, sedangkan yang mendekati 0 memiliki pengaruh yang sangat kecil.

Model PLS terdiri dari variabel laten endogen, variabel laten eksogen dan indikator. Model PLS pada penelitian ini terdiri dari satu variabel laten eksogen, satu variabel laten endogen dan 8 indikator. Variabel laten eksogen yaitu hubungan antar variabel serta model struktural dan model pengukurannya digambarkan dalam bentuk diagram lintas (path diagram), sedangkan variabel laten endogen adalah variabel terikat yang dipengaruhi oleh variabel laten eksogen. Model hubungan antar variabel laten dibuat berdasarkan teori yang telah dijelaskan pada kerangka pemikiran. Variabel laten kompetensi kewirausahaan memiliki pengaruh pada variabel kinerja usaha. Notasi matematik dari model PLS dalam penelitian ini, yaitu model pengukuran variabel laten endogen kompetensi kewirausahaan (KK) dan model pengukuran variabel laten endogen kinerja usaha (KU) adalah sebagai berikut;

$\begin{array}{ll}\mathrm{X} .1=\lambda \mathrm{x} .1 & \mathrm{KK}+\varepsilon \mathrm{x} .1 \ldots \ldots \ldots(1) \\ \mathrm{X} .2=\lambda \mathrm{x} .2 & \mathrm{KK}+\varepsilon \mathrm{x} .2 \ldots \ldots \ldots(2) \\ \mathrm{X} .3=\lambda \mathrm{x} .3 & \mathrm{KK}+\varepsilon \mathrm{x} .3 \ldots \ldots \ldots(3) \\ \mathrm{X} .4=\lambda \mathrm{x} .4 & \mathrm{KK}+\varepsilon \mathrm{x} .4 \ldots \ldots \ldots .(4) \\ \mathrm{X} .5=\lambda \mathrm{x} .5 & \mathrm{KK}+\varepsilon \mathrm{x} .5 \ldots \ldots \ldots(5) \\ \mathrm{Y} .1=\lambda y .1 & \mathrm{KU}+\varepsilon y .1 \ldots \ldots \ldots(6) \\ \mathrm{Y} .2=\lambda y .2 & \mathrm{KU}+\varepsilon y .2 \ldots \ldots \ldots(7) \\ \mathrm{Y} .3=\lambda y .3 & \mathrm{KU}+\varepsilon y .3 \ldots \ldots \ldots . .(8)\end{array}$

Keterangan;

KK = variabel laten endogen

kompetensi kewirausahaan

$\mathrm{KU} \quad=$ variabel laten endogen kinerja usaha

$\mathrm{X} 1, \ldots \ldots \mathrm{n}=$ variabel manifest pada

variable laten eksogen

$\mathrm{Y} 1, \ldots . . \mathrm{n}=$ variabel manifest pada

variable laten endogen

$\lambda x .1, \ldots \mathrm{n}=$ muatan faktor variable pada

laten eksogen

$\lambda y .1, \ldots \mathrm{n}=$ muatan faktor variable pada

laten endogen

$\delta, \varepsilon=$ error pada model hubungan variabel

Variabel laten eksogen dalam penelitian ini yaitu kompetensi kewirausahaan $(\mathrm{KK})$, dan variabel laten endogen, yaitu kinerja usaha. Indikator kompetensi usaha dalam penelitian ini adalah kemampuan manajerial (X.1), kemampuan konseptual (X.2), kemampuan sosial (X.3), kemampuan membuat keputusan (X.4), dan kemampuan mengatur waktu (X.5), sedangkan indikator kinerja usaha adalah pendapatan (Y.1), keuntungan (Y.2). dan volume penjualan (Y.3).

Penting untuk dievaluasi, apakah di dalam model pengukuran variabel manifestnya dapat mengukur variabel laten (konstruk) dengan benar. Salah satu yang dapat dilakukan adalah dengan cara menilai tingkat validitas variabel manifest berdasarkan nilai loading factor $(\lambda)$, apakah lebih besar atau lebih kecil dari 0.5. Jika nilai loading factor menunjukkan lebih besar dari 0.5, maka variabel manifest dinyatakan baik (valid) untuk mengukur variabel laten. Namun jika menunjukkan angka lebih kecil dari 0.5 , maka variabel manifest harus dibuang karena tidak baik untuk mengukur variabel laten.

Dalam model PLS, model yang diuji dapat menggunakan asumsi; data tidak 
harus berdistribusi normal; skala pengukuran boleh berupa nominal, ordindal, interval dan rasio; indikator boleh relfektif maupun formatif; dan tidak harus berdasarkan teori (Latan dan Ghozali, 2015). Pengujian hipotesis dinilai berdasarkan nilai t-statistik. Kriteria untuk menolak dan menerima hipotesis yang diajukan dinilai berdasarkan perbandingan nilai t-hitung dan t-tabel. Apabila nilai thitung lebih besar dari pada t-tabel maka hipotesis diterima. Namun apabila t-hitung lebih kecil dari pada t-tabel, maka hipotesis ditolak. Pada penelitian ini menggunakan alpha 5 persen. Nilai t-tabel untuk aplha $5 \%$ adalah 1,96 .

\section{HASIL PENELITIAN DAN PEMBAHASAN}

\section{Hasil Penelitian}

\section{Identitas responden}

Dari 60 orang responden, terdapat beberapa karakteristik yang diteliti yaitu jenis kelamin didominasi oleh laki-laki (85 persen), pada usia responden tedapat perbedaan antara skala mikro dan skala kecil dimana pada skala kecil 96,67 persen adalah kaum muda (dewasa awal) dengan rentang usia 18-40 tahun sedangkan skala mikro didomasi 60 persen dewasa madya dengan rentang usia 40-60 tahun. Umumnya kaum muda memiliki pengalaman yang rendah, namun memiliki Nilai loading factor motivasi, kebutuhan berprestasi dan kekosmopolitan yang tinggi.

Tingkat pendidikan juga terdapat perbedaan antara skala mikro dan skala kecil dimana 66,67 persen skala kecil adalah diploma dan sarjana sedangkan skala mikro 63,33 persen adalah tamat SMA. Hal ini menunjukkan tingkat pendidikan responden skala mikro masuk dalam kategori rendah dibanding skala kecil. Tingkat pendidikan yang rendah menggambarkan kemampuan sumber daya manusia yang relatif rendah. Pelaku usaha yang pernah mengikuti pelatihan hanya pelaku usaha skala kecil. Hal ini menujukkan masih kurangnya minat pelaku usaha skala mikro untuk meningkatkan kemampuan diri.

Orang yang senang datang ke kedai kopi skala mikro biasanya masyarakat menengah ke bawah, seperti ojek online, supir angkot, karyawan dengan gaji kecil dan mahasiswa. Mayoritas pengguna kedai kopi skala mikro berjenis kelamin laki-laki. Umunya pengunjung yang datang untuk menikmati segelas kopi dengan mie instan atau roti bakar. Kedai kopi skala kecil lebih disenangi oleh masyarakat menengah ke atas seperti pengusaha, karyawan bergaji besar dan mahasiswa yang mempunyai pendapatan besar. Tidak hanya laki-laki, para wanita juga senang datang ke tempat ini.

Tabel-4: Nilai Loading Factor $(\lambda)$ Model Skala Kecil

\begin{tabular}{llcc}
\hline Variabel Laten & \multicolumn{1}{c}{ Variabel Manifest } & \multicolumn{1}{c}{$\boldsymbol{\Lambda}$} & Keterangan \\
\hline Kompetensi & Kemampuan Manajerial $\left(\mathrm{X} .1_{1}\right)$ & 0.926 & Valid \\
\cline { 2 - 4 } kewirausahaan & Kemampuan Konseptual (X.2) & 0.966 & Valid \\
\cline { 2 - 4 } & Kemampuan Sosial (X.3) & 0.959 & Valid \\
\cline { 2 - 4 } & $\begin{array}{l}\text { Kemampuan Membuat } \\
\text { Keputusan (X.4) }\end{array}$ & 0.938 & Valid \\
\cline { 2 - 4 } & $\begin{array}{l}\text { Kemampuan Mengatur Waktu } \\
\text { (X.5) }\end{array}$ & 0.953 & Valid \\
\hline Kinerja usaha & Penerimaan (Y.1) & 0.991 & Valid \\
\cline { 2 - 4 } & Keuntungan (Y.2) & 0,992 & Valid \\
\hline
\end{tabular}




\begin{tabular}{lll}
\hline Volume Penjualan (Y.3) & 0.993 & Valid \\
\hline
\end{tabular}

Tabel-5: Nilai Loading Factor ( $\lambda$ ) Model Skala Mikro

\begin{tabular}{llcc}
\hline Variabel Laten & \multicolumn{1}{c}{ Variabel Manifest } & \multicolumn{1}{c}{$\boldsymbol{\Lambda}$} & Keterangan \\
\hline Kompetensi & Kemampuan Manajerial (X.1) & 0.781 & Valid \\
\cline { 2 - 4 } Kewirausahaan & Kemampuan Konseptual (X.2) & 0.922 & Valid \\
\cline { 2 - 4 } & Kemampuan Sosial (X.3) & 0.879 & Valid \\
\cline { 2 - 4 } & $\begin{array}{l}\text { Kemampuan Membuat } \\
\text { Keputusan (X.4) }\end{array}$ & 0.883 & Valid \\
\cline { 2 - 4 } & $\begin{array}{l}\text { Kemampuan Mengatur Waktu } \\
(\mathrm{X} .5)\end{array}$ & 0.849 & Valid \\
\hline Kinerja Usaha & Penerimaan (Y.1) & 0.982 & Valid \\
\cline { 2 - 4 } & Keuntungan (Y.2) & 0,989 & Valid \\
\cline { 2 - 4 } & Volume Penjualan (Y.3) & 0,984 & Valid \\
\hline
\end{tabular}

Berdasarkan hasil evaluasi model semua variabel indikator dalam model ini pengukuran ini dapat diketahui bahwa dapat menjelaskan variabel latennya.

Nilai AVE dan compose reliability

Tabel-6: Nilai AVE dan Compose Reliability Model Skala Mikro

\begin{tabular}{lccc}
\hline Variabel laten & $\begin{array}{c}\text { Average Variance } \\
\text { Extracted }(\boldsymbol{A V E})\end{array}$ & $\begin{array}{c}\text { Compose } \\
\text { Reliablity }\end{array}$ & Keterangan \\
\hline Kompetensi & 0.747 & 0.936 & Baik \\
kewirausahaan & 0.971 & 0.990 & Baik \\
Kinerja usaha & &
\end{tabular}

Berdasarkan tabel-6, seluruh variabel memiliki nilai AVE diatas 0.5 dan compose reliability di atas 0.7 , model kedai kopi skala mikro dinyatakan memiliki reliabilitas yang baik. Pada model final memberikan hasil yang reliable. Syarat model yang reliable adalah model yang memiliki nilai AVE dan compose reliability lebih dari 0.5 dan 0.7. Model yang memiliki realibilitas yang cukup baik artinya seluruh indikator yang digunakan dapat dipercaya mengukur konstruknya.

Tabel-7: Nilai AVE dan Compose Reliability Model Skala Kecil

\begin{tabular}{lccc}
\hline \multicolumn{1}{c}{ Variabel Laten } & $\begin{array}{c}\text { Average Variance } \\
\text { Extracted }(\boldsymbol{A V E})\end{array}$ & $\begin{array}{c}\text { Compose } \\
\text { Reliablity }\end{array}$ & Keterangan \\
\hline $\begin{array}{l}\text { Kompetensi } \\
\text { kewirausahaan }\end{array}$ & 0.984 & 0.978 & Baik \\
Kinerja usaha & 0.900 & 0.995 & Baik \\
\hline
\end{tabular}

Pada tabel-7, seluruh variabel memiliki nilai AVE diatas 0.5 dan compose reliability di atas 0.7 , model kedai kopi skala kecil dinyatakan memiliki reliabilitas yang baik. Tahap selanjutnya pada evaluasi model pengukuran adalah menguji unidimensionalitas dari model dengan menggunakan indikator alpha cronbach 
dengan indikator apabila di atas 0.7 , dinyatakan baik.

\section{Cronbach alpha}

Tabel-8: Cronbach Alpha Model Skala Mikro

\begin{tabular}{lcc}
\hline \multicolumn{1}{c}{ Variabel laten } & Cronbach Alpha & Keterangan \\
\hline $\begin{array}{l}\text { Kompetensi } \\
\text { kewirausahaan }\end{array}$ & 0.915 & Baik \\
Kinerja usaha & 0.985 & Baik \\
\hline
\end{tabular}

Pada tabel-8, nilai cronbach alpha model skala mikro pada seluruh variabel di

atas 0.7 , model dinyatakan memiliki unidimensionalitas yang baik.

\section{Tabel-9: Cronbach Alpha Model Skala Kecil}

\begin{tabular}{lcc}
\hline Variabel Laten & Cronbach Alpha & Keterangan \\
\hline Kompetensi & 0.972 & Baik \\
kewirausahaan & 0.992 & Baik \\
Kinerja usaha & & \\
\hline
\end{tabular}

Berdasarkan tabel-9, nilai cronbach alpha model skala kecil di atas 0.7 , seluruh variabel memiliki unidimensionalitas yang baik. Selanjutnya adalah mengevaluasi dengan melihat discriminant validity. Tahap ini adalah untuk memastikan konstruk yang berbeda harusnya tidak berkorelasi dengan tinggi. Cara menguji discriminant validity dapat menggunakan metode Fornell dan Larcker (1981) yang menjelaskan discriminant validity dapat dilihat melalui nilai cross loading yang harus lebih besar dari 0.50 , artinya minimal 50 persen variasi dari indikator dapat dijelaskan.

\section{Nilai cross loading}

Tabel-10: Nilai Cross Loading

\begin{tabular}{lrcrc}
\hline \multirow{2}{*}{ Variabel laten } & \multicolumn{2}{c}{ Skala kecil } & \multicolumn{2}{c}{ Skala mikro } \\
\cline { 2 - 5 } & $\begin{array}{c}\text { Cross } \\
\text { Loading }\end{array}$ & Keterangan & $\begin{array}{c}\text { Cross } \\
\text { Loading }\end{array}$ & Keterangan \\
\hline $\begin{array}{l}\text { Kompetensi } \\
\text { kewirausahaan }\end{array}$ & 0.928 & Valid & 0.613 & Valid \\
Kinerja usaha & 0.992 & Valid & 0.985 & Valid \\
\hline
\end{tabular}

Model skala mikro dan kecil diperoleh nilai cross loading seluruh variabel lebih besar dari 0.500 yang dapat dilihat pada Tabel-10. Hal ini menunjukkan bahwa tidak ada masalah discriminant validity pada seluruh model yang telah dievaluasi ini.
Setelah memenuhi semua persyaratan, model dinyatakan menjadi model final. Berdasarkan model final, diperoleh variabel manifest yang memenuhi syarat. Pada model skala kecil diperoleh variabel yang memenuhi syarat, yaitu variabel laten kompetensi kewirausahaan direfleksikan oleh 
kemampuan manajerial (Y.1), kemampuan konseptual (Y.2), kemampuan sosial (Y.3), kemampuan membuat keputusan (Y.4) dan kemampuan mengatur waktu (Y.5). Variabel laten kinerja usaha direfleksikan oleh pendapatan (Y.1). keuntungan (Y.2) dan volume penjualan (Y.2). Hal in juga berlaku pada model skala mikro.

\section{Evaluasi model struktural}

Model struktural dapat dievaluasi dengan melihat $R$-square $\left(\mathrm{R}^{2}\right)$ pada variabel endogen dan nilai estimasi koefisien parameter jalur (Stone 1974 dan Giesser 1975 dalam Ghozali 2012). Model yang kuat adalah model yang memiliki $R$-square sebesar 0.75 sedangkan model yang lemah jika memiliki $R$-square sebesar 0.25 .

Tabel-11: Sebaran Nilai $R$-square

\begin{tabular}{ccc}
\hline Variabel Laten & \multicolumn{2}{c}{$R$-square } \\
\cline { 2 - 3 } Endogen & Skala kecil & Skala mikro \\
\hline Kinerja usaha & 0.862 & 0.376 \\
\hline
\end{tabular}

Nilai $R$-square variabel kinerja usaha model kedai kopi skala kecil adalah 0.862 (kuat) dan dapat dilihat pada Tabel-11, yang artinya faktor-faktor yang digunakan untuk mengukur kompetensi kewirausahaan dan kinerja usaha, mampu menjelaskan keragaman nilai kinerja usaha sebesar 86.2 persen, sisanya dijelaskan oleh variabel lain yang tidak ada di dalam model. Nilai $R$-square variabel kinerja usaha kedai kopi model skala mikro adalah 0.376 (medium), yang artinya faktor-faktor yang digunakan untuk mengukur kompetensi kinerja usaha, mampu menjelaskan keragaman nilai kinerja usaha sebesar 37.6 persen, sisanya dijelaskan oleh variabel lain yang tidak ada di dalam model.

Tahap selanjutnya adalah melihat nilai $Q$-square (predictive relevance) untuk mengukur seberapa baik nilai observasi yang dihasilkan model serta estimasi paramaternya. Nilai $Q$-square lebih besar dari 0 berarti model memiliki predictive relevance dan sebaliknya apabila $Q$-square lebih kecil dari 1, maka model kurang memiliki precitive relevance. Nilai $Q$ square memiliki rentang antara 0 sampai 1 dimana semakin mendekati 1 maka semakin baik. $Q$-square skala kecil $=1-(1$ - 0.862) $=1-0.138=0.962$, sedangkan $Q$ - square skala mikro $=1-(1-0.376)=1-$ $0.624=0.476$.

Hasil perhitungan $Q$-square model skala kecil adalah 0.962 yang berarti model dapat menjelaskan 96.2 persen dari fenomena yang terjadi dan sisanya dijelaskan oleh variabel lain yang tidak ada dalam model. $Q$-square model skala mikro adalah 0.476 yang berarti model dapat menjelaskan 47.6 persen dari fenomena yang terjadi dan sisanya dijelaskan oleh variabel lain yang tidak ada dalam model.

\section{Model final pengaruh kompetensi kewirausahaan terhadap kinerja usaha}

Setelah memenuhi semua persyaratan maka model dinyatakan menjadi model final. Berdasarkan model final maka diperoleh variabel manifest yang memenuhi syarat. Variabel laten kompetensi kewirausahaan baik model skala mikro dan skala kecil direfleksikan oleh kemampuan manajerial (X1.1), kemampuan konseptual (X1.2), kemampuan sosial (X1.3), kemampuan membuat keputusan (X1.4) dan kemampuan mengatur waktu (X1.5). Variabel laten kinerja usaha baik skala mikro maupun skala kecil direfleksikan oleh keuntungan (Y1.1) dan volume 
penjualan (Y1.2). Model final dapat dilihat dalam gambar-1 dan gambar-2.

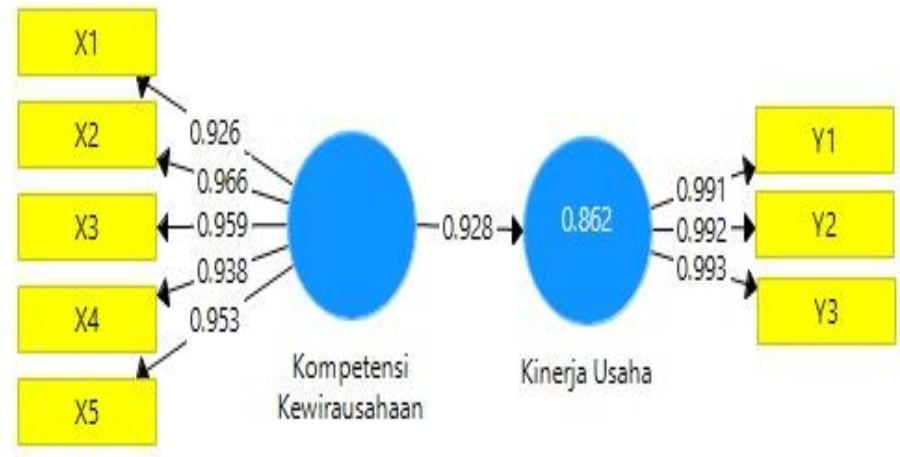

Gambar-1: Model Final Kedai Kopi Skala Kecil

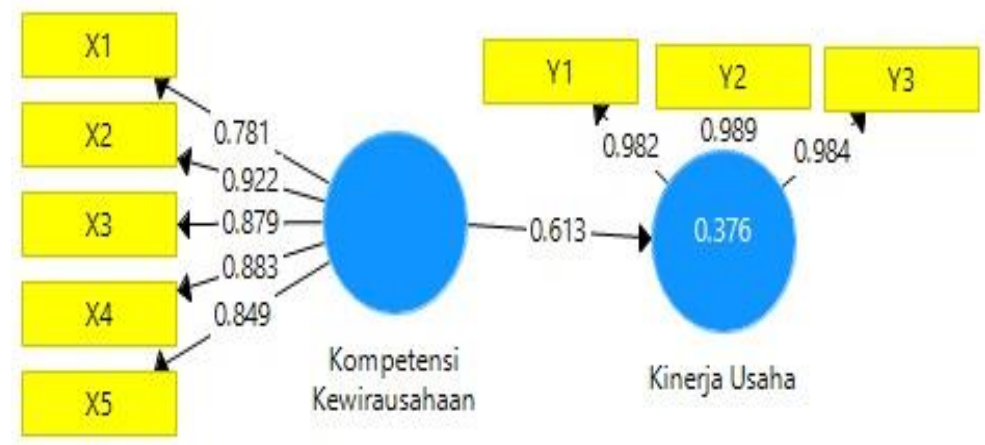

Gambar-2: Model Final Kedai Kopi Skala Mikro

Nilai koefisien jalur kompetensi kewirausahaan terhadap kinerja usaha pada model skala kecil (coffee shop) lebih tinggi dibandingkan skala mikro (warung kopi) dengan nilai masing masing 0.928 dan 0.613 yang dapat dilihat dalam gambar-1 dan gambar-2. Hal ini mengindikasikan bahwa kompetensi kewirausahaan model skala kecil lebih kuat mempengaruhi kinerja usaha dibandingkan model skala mikro.

Pengaruh kompetensi kewirausahaan terhadap kinerja usaha

Tabel-12:. T-hitung Model Skala Kecil

\begin{tabular}{lccc}
\hline \multicolumn{1}{c}{ Hipotesis } & t-hitung & p-value & Keterangan \\
\hline $\begin{array}{l}\text { Kompetensi Kewirausahaan --> } \\
\text { Kinerja usaha }\end{array}$ & $47.565^{*}$ & $0.000^{*}$ & Signifikan \\
\hline
\end{tabular}

Keterangan: *p-value $<0,05=$ signifikan, *t(0.05): 1.96

Tabel-13: T-hitung Model Skala Mikro

\begin{tabular}{lccc}
\hline \multicolumn{1}{c}{ Hipotesis } & t-hitung & p-value & Keterangan \\
\hline $\begin{array}{l}\text { Kompetensi Kewirausahaan --> } \\
\text { Kinerja Usaha }\end{array}$ & $5.171 *$ & $0.000 *$ & Signifikan \\
\hline
\end{tabular}

Keterangan: *p-value $<0,05=$ signifikan, $* t(0.05): 1.96$ 
Berdasarkan tabel-12 dan tabel-13, kompetensi kewirausahaan berpengaruh signifikan terhadap kinerja usaha baik skala mikro maupun skala kecil dengan nilai pvalue $<0.05$.

\section{Pembahasan}

Kompetensi kewirausahaan mendukung peningkatan kinerja usaha baik skala mikro maupun skala kecil. Hal ini sesuai dengan hasil penelitian yang dilakukan oleh Aliyu (2017) yang menyimpulkan bahwa kompetensi kewirausahaan berpengaruh signifikan terhadap kinerja usaha di Nigeria, sedangkan hasil penelitian yang dilakukan oleh Tehsen dan Ramayah (2015), yang menyimpulkan bahwa kompetensi kewirausahaan berhubungan dengan kinerja usaha, daya saing, pertumbuhan dan kesuksesan perusahaan. Penelitian ini didukung juga hasil penelitian yang dilakukan oleh Radzi et al. (2017) yang meneliti tentang pengaruh faktor internal yang terdiri dari entrepreneurial competency, marketing capability, financial resources, technology usage dan knowledge sharing terhadap business succees. Penelitian tersebut membuktikan bahwa hanya kompetensi kewirausahaan yang berpengaruh positif terhadap keberhasilan usaha.

\section{KESIMPULAN DAN SARAN}

\section{Kesimpulan}

Kompetensi kewirausahaan kedai kopi skala kecil dan mikro dapat ditingkatkan melalui kemampuan manajerial, kemampuan konseptual, kemampuan sosial, kemampuan membuat keputusan, dan kemampuan mengatur waktu. Di antara lima indikator tersebut, kompetensi kewirausaan yang paling mempengaruhi adalah kemampuan konseptual pada kedua model. Kompetensi kewirausahaan mendukung peningkatan kinerja usaha kedai kopi skala kecil dan mikro. Kompetensi kewirausahaan kedai kopi skala kecil lebih mendukung peningkatan kinerja usaha dibandingkan pada kedai kopi skala mikro.

\section{Saran}

Perlu dilakukan penelitian lanjutan mengenai kedai kopi skala kecil maupun mikro pada aspek kewirausahaan yang lain, misalnya jiwa kewirausahaan, intensi kewirausahaan, dan sebagainya.

\section{DAFTAR PUSTAKA}

Aliyu, MS. 2017. Entrepreneurial Competencies and the Performance of Small and Medium Enterprises (SMEs) in Zaria Local Government Area of Kaduna State. International Journal of Entrepreneurial Development, Education and Science Research (IJEDESR). 4(2):116-138.

Baum, J. Robert, Edwin A. Locke dan Ken G. Smith, 2001. A Multidimensional Model Of Venture Growth. Academic Management Journal. 44(2):292-303. Bergevoet RHM, Ondersteizin CJM, Saatkamp HW, Woerkum Van CMJ, Huirme RBM. 2004. Entrepreneurship Behavior pf Dutch Dairy Farmer Under Milk Quota System Goal, Objectives dan Attitudes. Wageningen (NL): Elsevier. 80(1): 1-21.

Ghozali I, Latan H. 2015. Partial Least Square, Konsep, Teknik dan Aplikasi Menggunakan Program SmartPLS 3.0 Untuk Penelitian Empiris. Semarang: Badan Penerbit Universitas Diponegoro

International Coffee Organization. 2017. Konsumsi Kopi Indonesia. Jakarta : ICO. 
Isa M. 2013. Analisis Kompetensi Kewirausahaan, Orientasi Kewirausahaan dan Kinerja Industri Mebel. Jurnal Manajamen dan Bisnis.

Kuratko FD, Hogetts MR. 2007. Entrepreneurship: Theory, Process and Practice. Canada (US): Thomson South-Western.7.

Nurhayati P, Heny KS, Tintin S, Yanti NM. 2011. Analisis Pengaruh Karakteristik Kewirausahaan Terhadap Kinerja Wirausaha Pada Unit UMKM Di Kabupaten Bogor. Bogor: Prosiding Seminar Unggulan Departemen Agribisnis.

Muharastri Y. 2013. Karakteristik Wirausaha, Kompetensi Kewirausahaan dan Kinerja Usaha Peternakan Sapi Perah di KTTSP Kania Bogor. Tesis. Bogor (ID). Institut Pertanian Bogor.

Moeheriono. 2009. Pengukuran Kinerja Berbasis Kompetensi. Jakarta (ID):Ghalia Indonesia.

Rahman SA, Ahmad NH, Taghizadeh SH. 2016. Entrepreneurial Competencies of BoP Entrepreneurs in Bangladesh to Achieve Business Success. Journal of General Management. 42(1):4563.

Tehseen, S., and Ramayah, T. 2015. Entrepreneurial Competencies and SMEs Business Success: The Contingent Role of External Integration. Mediterranean Journal of Social Sciences. 6 (1):50-61. 
